\title{
Copper tolerance of the life history stages of the splashpool copepod Tigriopus californicus (Copepoda, Harpacticoida)
}

\author{
Patrick O'Brien, H. Feldman*, E. V. Grill, A. G. Lewis** \\ Department of Oceanography, University of British Columbia, 6270 University Blvd., Vancouver, British Columbia, \\ Canada V6T 1W5
}

\begin{abstract}
High concentrations of copper were used to test the hypothesis that a species tolerant to large changes in natural conditions will exhibit tolerance to elevated levels of chemical contamination. The harpacticoid copepod Tigriopus californicus was used as a test species because it occurs in supralittoral splashpools and is tolerant to wide-ranging conditions of temperature and salinity. Life history stages were exposed to concentrations of total dissolved copper between $10^{-7}$ and $10^{-5} \mathrm{M}$ in a defined medium without organic metal-complexing agents and without food. The $96-\mathrm{h} \mathrm{LC}_{50}$ and $\mathrm{LC}_{95}$ values were higher for the egg (= embryo) than for most of the naupliar stages. They were highest for the adult. With the exception of the adult, the $96-\mathrm{h} \mathrm{LC}_{50}$ values for total copper were within the range of 24-h and 48-h $\mathrm{LC}_{50}$ values reported for other copepods in copper-enriched natural seawater When considered in terms of cupric ion activity, however, $T$. californicus tolerated levels of activity 2 to 3 orders of magnitude higher than those reported for other copepods. These results support the hypothesis that innate tolerance to extremes of natural environmental conditions correlate with tolerance to chemical contamination. They also suggest that natural tolerance must be considered in the selection of bioassay organisms.
\end{abstract}

\section{INTRODUCTION}

To survive at high levels of biologically available metal an organism must either exhibit an innate tolerance or be able to isolate the metal through some biochemical mechanisms such as the use of metallothionein-like agents (e.g. Roesijadi 1981). There has been relatively little work comparing tolerance to anthropogenic metal or other chemicals with the natural tolerance of the organism to environmental conditions. Ritz (1980) found copper tolerance in 2 intertidal amphipods to be more pronounced in the brackish-water species, which would be the most environmentally tolerant. Sabourin et al. (1985) suggest that the response of coastal and estuarine fishes to anthropogenic materials may be influenced by their tolerance to large changes in environmental parameters. Greater survival of naturally tolerant organisms is

\footnotetext{
- Present address: Department of Zoology, University of Cambridge, Cambridge, England

- Addressee for reprint requests
}

of interest because it can affect the species composition of continuously polluted environments and can influence the ultimate biological impact of episodic chemical contamination. Tolerance must be considered when selecting bioassay organisms; naturally tolerant species are usually easy to maintain in culture but are less sensitive than intolerant species.

This study used the splashpool harpacticoid copepod Tigriopus californicus and high concentrations of dissolved copper to test the hypothesis that a species exhibiting tolerance to large changes in natural conditions will exhibit tolerance to elevated levels of chemical contaminants. Copper is an essential metal that can be toxic at elevated concentrations if it is present in a biologically available form, able to be taken up by the organism and react with its metabolic machinery. Because of the importance of knowing the biological availability of the metal, a completely defined medium was used in the study. Since the sensitivity of an organism can change during its life history, the tolerance of each of the life history stages was measured. Sensitivity to copper was measured in terms of mortality, using 
96- $h L^{-C_{50}}$ and $L C_{95}$ values calculated from the mortality data. These values were compared with those published for other marine copepods to provide an indication of relative tolerance for the test species.

\section{MATERIALS AND METHODS}

Laboratory cultures of the harpacticoid copepod Tigriopus californicus have been maintained since the late 1960 's, from specimens collected in a splashpool on the west coast of Vancouver Island. For the present study, cultures were maintained at $35 \mathrm{ppt}$ salinity and $\mathrm{pH}$ 8.0, in 2.8 1 Pyrex Fernbach flasks and a salt solution (SOW) from an artificial seawater medium (AQUIL; Morel et al. 1979). The salt solution was passed through an ion exchange resin (Chelex-100, 100-200 mesh, BioRad Laboratories) to reduce the concentration of metal contaminants from the reagent grade salts. (Chelex100 was obtained in the $\mathrm{Na}^{+}$form and was converted to the ionic form and $\mathrm{pH}$ of the solution to be purified to avoid any alkalinity changes that might occur in the medium.) Temperature was maintained at $16 \pm 1{ }^{\circ} \mathrm{C}$ on a 16:8 h light:dark cycle. The culture medium was replaced every 96 to $120 \mathrm{~h}$. Cultures were fed finely ground fish food (Wardley's Basic Food Flakes) every $24 \mathrm{~h}$. Since the cultures were not axenic, bacteria are presumed to have formed an important food source, at least for the younger life history stages.

Copepods to be used in experiments were isolated from the laboratory stocks at the egg stage. Females with mature egg clusters were isolated on a glass slide, in a drop of water, and the egg sac was removed with stainless steel dissecting forceps. (Preliminary work found that mortality among egg clusters was high when they were isolated from the female less than $48 \mathrm{~h}$ after egg extrusion.) Egg clusters were washed 3 times with SOW before being transferred to acid-washed (1N HCl) $20 \mathrm{ml}$ incubation chambers (Nunclon Incubation Chambers ${ }^{\mathrm{tm}}$ or comparable chambers). Hatched nauplii were maintained in acid-washed $70 \times 50 \mathrm{~mm}$ Pyrex crystallizing dishes until they reached the stage to be tested. Specimens were then transferred through 3 rinses of SOW and subsequently isolated in SOW for 6 to $8 \mathrm{~h}$ prior to their use. This was to allow for depuration and to reduce the concentration of metabolites which might affect metal bioavailability. Immediately prior to use the specimens were isolated in a solution identical to that used in the test. Test solutions were replaced every $24 \mathrm{~h}, 3$ replicates were run for each test, each replicate used 20 individuals, all tests were run in a food-free environment, observations were made and dead organisms removed every $24 \mathrm{~h}$. All bioassays were run for $96 \mathrm{~h}$ even though the duration of the life history stage was often less than $96 \mathrm{~h}$.
Thus the term 'stage' should be considered only as a starting point for the test.

Polystyrene Nunclon Incubation Chambers ${ }^{\mathrm{tm}}$ were initially soaked in $1 \mathrm{~N} \mathrm{HCl}$ for $7 \mathrm{~d}$ and then rinsed with glass-distilled water (GDW). Prior to subsequent use the chambers were soaked in $1 \mathrm{~N} \mathrm{HCl}$ for $4 \mathrm{~d}$ and then rinsed 3 times with GDW to remove sorbed organics and metals. Ten $\mathrm{ml}$ of the experimental solutions was allowed to equilibrate with the chambers for at least $2 \mathrm{~h}$ before use. These solutions were then replaced with fresh solution and the test organisms added. All transfers were made in a plastic-lined laminar flow hood in which metal parts were replaced with polypropylene where possible.

SOW was prepared as described in Morel et al. (1979). $\mathrm{pH}$ was adjusted to $8.0 \pm 0.05$ by bubbling with acid-cleaned $\left(1 \mathrm{~N} \mathrm{H}_{2} \mathrm{SO}_{4}\right)$, filtered $(0.4 \mu \mathrm{m})$ air. The copper stock was prepared separately, by dissolving metal in reagent grade $1 \mathrm{NHNO}_{3}$. GDW was added to adjust the final metal stock concentration to $1 \times 10^{-3}$ $M$. Acid-cleaned polypropylene bottles and volumetric flasks were used in the preparation and storage of metal stocks. Enough metal stock was added to the SOW to achieve the desired copper concentration. Ionic strength of the SOW was 0.72 . (The ionic strength is a stoichiometric value calculated on the basis of the total concentrations of the individual ions. It is provided since it affects the value of the mean ion activity coefficient.) The relationship between cupric ion activity $\left(\mathrm{a}_{\mathrm{Cu}^{2+}}\right)$ and total copper $\left(\mathrm{C}^{\mathrm{T}} \mathrm{Cu}^{z^{+}}\right)$is:

$$
\mathrm{a}_{\mathrm{Cu}^{2+}}=0.022 \times \mathrm{C}^{\mathrm{T}} \mathrm{Cu}^{2+}
$$

This relationship was obtained by first determining the speciation of the major seawater ions using the data and procedures described by Millero \& Schreiber (1982). The fraction of the dissolved copper occurring as free ions was then estimated using the stability constants given in Turner et al. (1981) and the activity coefficient correction procedures of Millero \& Schreiber (1982). The value given above as the total-ion activity coefficient $(0.022)$ was finally obtained by multiplying the free-ion activity coefficient $(0.22)$ by the fraction of the dissolved copper consisting of free ions (0.099). Changes in metal chemistry or metal concentration that may have occurred during the bioassay period are assumed not to have had significant effects on the results because of the high metal concentrations used and the daily replacement of test medium. However, frequent replacement of test solution reduces but does not eliminate the potential loss of metal that occurs in static bioassays (e.g. Ritz 1980).

Single-factor analysis of variance was used to determine the significance of differences between the means in the different groups of bioassays. Because the test results were expressed as a percent of the control, 
an arcsine manipulation (e.g. Zar 1984) was used to obtain a linear fit of the data. Concentrations of copper causing $50 \%$ mortality in $96 \mathrm{~h}\left(\mathrm{LC}_{50}\right)$ and $95 \%$ in $96 \mathrm{~h}$ $\left(\mathrm{LC}_{95}\right)$ were derived in the manner described in Standard Methods (1976).

\section{RESULTS AND DISCUSSION}

Tigriopus californicus inhabits supralittoral splashpools along the west coast of North America, from Baja California to Alaska, and can withstand extreme environmental changes (Burton et al. 1979, Dethier 1980, Burton 1985). It has been reported to survive at temperatures exceeding $40^{\circ} \mathrm{C}$ for a short time and to survive rapid changes of more than $10 \mathrm{C}^{\circ}$ (Burton et al. 1979, Dethier 1980). It remains active at salinities ranging from 6 to $102 \mathrm{ppt}$ and is reported to have survived a salinity of 334 ppt (Burton et al. 1979). Huizinga (1971) found normal feeding and reproductive behaviour at salinities up to $75.3 \mathrm{ppt}$.

The life history of Tigriopus californicus is similar to that of many free-living copepods. It consists of an embryonic or egg phase, 6 naupliar stages and 6 copepodite stages (not 5 as reported by Huizinga 1971). the last being the sexually mature adult. The size of the postembryonic life history stages increases with age, from (mean \pm 1 standard deviation) $116 \pm 8 \mu \mathrm{m}$ (first nauplius) to $1143 \pm 140 \mu \mathrm{m}$ (sixth copepodite). Sexual dimorphism is apparent at the fifth copepodite stage and a single fertilization (Fraser 1936, Harris 1973, Burton 1985) occurs shortly after the female moults into the sixth copepodite. Females produce up to 3 successive egg clusters under laboratory conditions and characteristically carry the eggs until they hatch. The adult or sixth copepodite stage is reached approximately $20 \mathrm{~d}$ after the extrusion of the eggs.
The 96-h $\mathrm{LC}_{50}$ and $\mathrm{LC}_{95}$ values for all life history stages are given in Table 1. Lowest values are found for the first and second naupliar stages while highest values are found for the sixth copepodite (adult). Arranged in order of increasing tolerance, the mean $96-\mathrm{h} \mathrm{LC}_{50}$ values are:

$$
\begin{gathered}
\mathrm{N}_{2}<\mathrm{N} 1<\mathrm{N} 3<\mathrm{N} 4<\mathrm{egg}<\mathrm{N} 5<\mathrm{N} 6< \\
\mathrm{C} 1<\mathrm{C} 5<\mathrm{C} 4<\mathrm{C} 3<\mathrm{C} 2<\mathrm{C} 6
\end{gathered}
$$

The order for the mean $96-\mathrm{h} \mathrm{LC}_{95}$ values is slightly different although it exhibits the same trends when one considers the $95 \%$ confidence limits:

$$
\begin{gathered}
\mathrm{N} 1<\mathrm{N} 2<\mathrm{N} 3<\mathrm{N} 4<\mathrm{N} 5<\mathrm{N} 6<\text { egg }< \\
\mathrm{C} 5<\mathrm{C} 1<\mathrm{C} 3<\mathrm{C} 4<\mathrm{C} 2<\mathrm{C} 6
\end{gathered}
$$

In neither case do the egg, C2 or C5 stages fit into a trend of increasing tolerance with age. The egg and $\mathrm{C} 2$ stages appear to have a greater tolerance and the C5 less tolerance than would be expected from the other stages. However, the $95 \%$ confidence limits (Table 1) indicate an overlap in tolerance between all of the copepodite stages except the C6. This suggests not only that the adult is more tolerant but also that there is a gradual rather than abrupt change in tolerance during ther preadult portion of the life cycle.

The 96-h $\mathrm{LC}_{95}$ values for the egg are significantly ( $p$ $<0.05)$ higher than for the $\mathrm{N} 1$ and the mean value is higher than all of the naupliar stages. The only comparable copepod life history data are for the harpacticoid Tisbe holothuriae. Moraitou-Apostolopoulou \& Verriopoulos (1979) and Verriopouios \& ivoraitou-Apostolopoulou (1982) report (Table 2) that resistance increases with age in the order 1 -d-old nauplii $<5$-dold nauplii $<10$ - $d$-old copepodites. They also found a somewhat higher sensitivity with the adult female than with 10-d-old copepodites (Table 2).

\begin{tabular}{|c|c|c|c|c|}
\hline Stage & $\begin{array}{c}\mathrm{LC}_{50} \\
\left(10^{-6} \mathrm{M}\right)\end{array}$ & $\left(10^{-7} \mathrm{Cu}\right)$ & $\begin{array}{c}\mathrm{LC}_{95} \\
\left(10^{-6} \mathrm{M}\right)\end{array}$ & $\underset{\left(10^{-7} \mathrm{M}\right)}{\mathrm{a}_{\mathrm{Cu}^{2}}}$ \\
\hline Egg & $3.6(1.3-6.2)$ & 0.79 & $9.6(7.0-13.1)$ & 2.1 \\
\hline N1 & $1.2(0.6-1.6)$ & 0.026 & $3.7(3.3-4.2)$ & 0.81 \\
\hline N2 & $0.3(0.02-2.0)$ & 0.066 & $4.7(3.0-8.0)$ & 1.0 \\
\hline N3 & $2.5(0.9-3.9)$ & 0.55 & $8.0(6.6-9.8)$ & 1.8 \\
\hline N4 & $2.9(1.5-4.2)$ & 0.64 & $8.7(7.3-10.4)$ & 1.9 \\
\hline N5 & $4.1(3.3-5.0)$ & 0.90 & $8.8(7.9-9.9)$ & 1.9 \\
\hline N6 & $4.8(3.5-6.1)$ & 1.1 & $9.6(8.1-11.3)$ & 2.1 \\
\hline $\mathrm{C} 1$ & $5.9(4.6-7.2)$ & 1.3 & $11.0(9.6-12.6)$ & 2.4 \\
\hline $\mathrm{C} 2$ & $7.8(4.5-11.5)$ & 1.7 & $13.7(10.2-18.8)$ & 3.0 \\
\hline $\mathrm{C} 3$ & $6.5(5.0-8.2)$ & 1.4 & $11.2(9.5-13.3)$ & 2.5 \\
\hline $\mathrm{C} 4$ & $6.2(3.9-8.5)$ & 1.4 & $12.5(10.1-15.6)$ & 2.8 \\
\hline $\mathrm{C} 5$ & $6.2(4.5-7.9)$ & 1.4 & $10.6(8.8-12.9)$ & 2.3 \\
\hline C6 & $12.0(10.0-14.0)$ & 2.6 & $15.1(13.2-17.8)$ & 3.3 \\
\hline
\end{tabular}

Table 2 presents copper values reported to cause

Table 1. Tigriopus californicus. $96-\mathrm{h} \mathrm{LC}_{50}$ and $\mathrm{LC}_{95}$ values for the life history stages. Cupric ion activity (a $\mathrm{C}_{\mathrm{u}^{2+}}$ ) values are given for each LC value; $95 \%$ confidence limits in parentheses. Egg: embryonic phase; N: nauplius; C: copepodite 
Table 2. Copepod $\mathrm{LC}_{50}$ copper values from the literature. Values have been converted to molar values

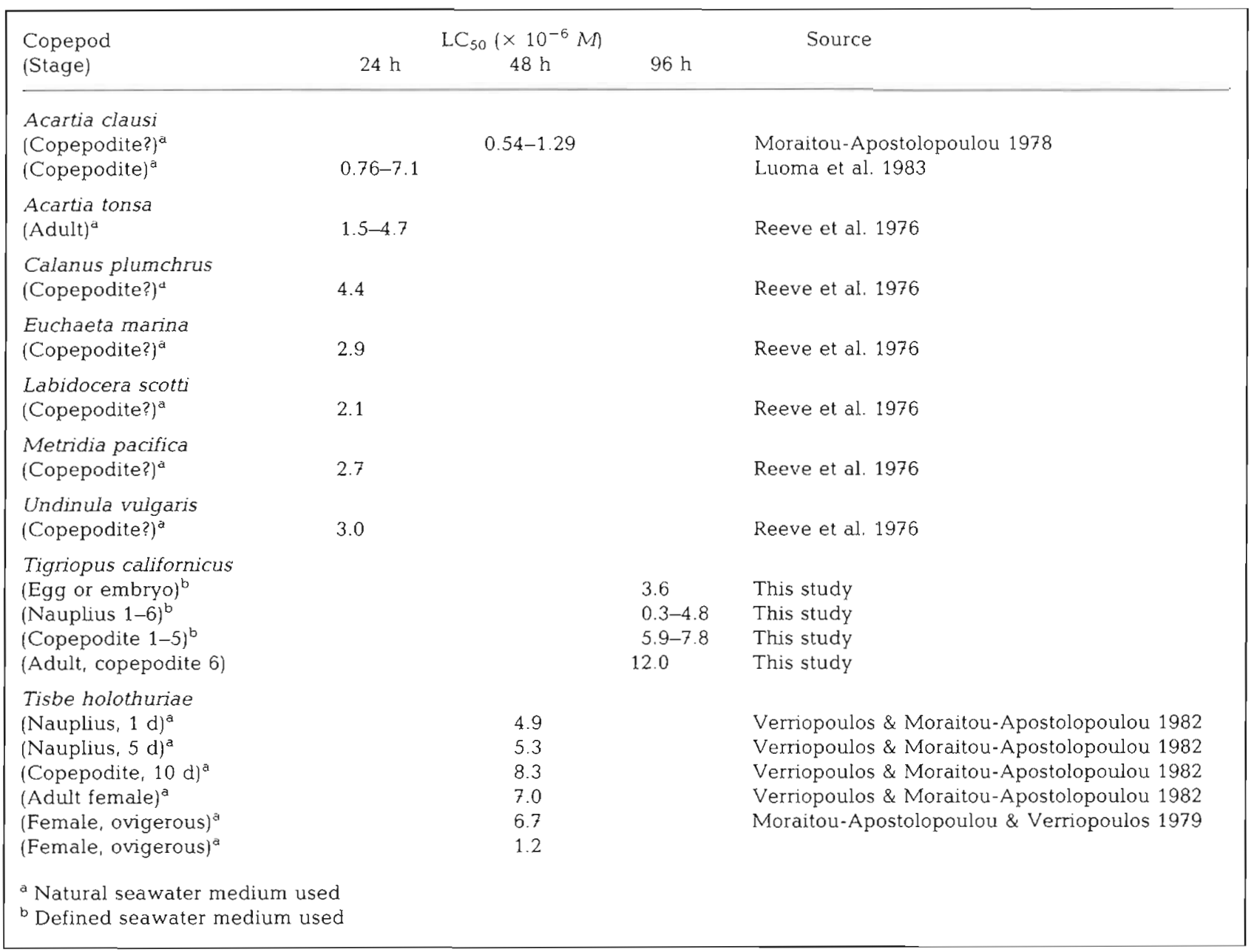

$50 \%$ mortality in different species of copepods. Values reported in the literature are for different exposure periods which makes comparisons difficult. In general, however, copper concentrations causing $50 \%$ mortality should decrease with exposure time. Thus a concentration producing $50 \%$ mortality after $24 \mathrm{~h}$ would be expected to be higher than that producing $50 \%$ mortality after $48 \mathrm{~h}$ or $96 \mathrm{~h}$. What this suggests is a higher tolerance for one species when the $96-\mathrm{h} \mathrm{LC}_{50}$ value is equal to or greater than the 48 -h or 24 - $h \mathrm{LC}_{50}$ value for a second species.

The 96-h $\mathrm{LC}_{50}$ levels of total copper in adult Tigriopus californicus are higher than those reported for other copepods (Table 2). The 96-h $\mathrm{LC}_{50}$ values for the first 5 copepodite stages are at the upper end of previously reported $24 \mathrm{~h}$ and $48-\mathrm{h} \mathrm{LC}_{50}$ values for various copepodite stages of other species. This suggests the possibility of increased tolerance although the lack of adequate stage recognition in literature on other copepods makes comparisons difficult. The $96-\mathrm{h} \mathrm{LC}_{50}$ values for the naupliar stages are wide-ranging, with the first 2 stages seemingly less tolerant then the nauplii of other copepods. However, other studies consider the naupliar stages collectively rather than individually (e.g. Sunda et al. 1987) or they refer to the age of the developing organism in days (Moraitou-Apostolopoulou \& Verriopoulos 1979). In addition, many earlier studies have used natural seawater while the present study used a defined seawater medium without organic metal-complexing agents. Natural seawater usually contains organic metal-complexing agents that will bind at least some of the copper and reduce its bioavailability (Wood 1983). Wood et al. (1983), for example, found that the concentration of copper necessary to produce a significant decrease in photosynthetic rate of naturally occurring phytoplankton assemblages was greater than the copper complexing capacity of the seawater. The presence of natural organic copper complexing agents thus increases the concentration of metal necessary to achieve a toxic 
effect. This produces artificially high LC values. As a result, the copper tolerance of previously examined copepods is probably lower than indicated by the seawater LC values in Table 2.

Sunda et al. (1987) used seawater modified by the addition of metal and metal-complexing agents to provide specific levels of calculated metal ion activity. They discuss the effects of cupric and zinc ion activities on the survival and reproduction of 3 species of fieldcaught calanoid copepods, 2 of which are discussed here. Tabular lethal concentration data are not avail'ble for copper alone but they report that a cupric ion activity of $10^{-10} \mathrm{M}$ caused total mortality of adult Acartia tonsa after $72 \mathrm{~h}$ and little survival of adult Centropages typicus after $48 \mathrm{~h}$. Naupliar survival of $A$. tonsa was reduced at a cupric ion activity of $10^{-11} \mathrm{M}$. The calculated cupric ion activity values (Table 1) for Tigriopus californicus are much higher than those for both $A$. tonsa and $C$. typicus and indicate a much greater tolerance of copper. The $96-\mathrm{h} \mathrm{LC}_{50}$ cupric ion activity value for the most sensitive life history stage of $T$. californicus (second nauplius) is $2.6 \times 10^{-9} \mathrm{M}$, approximately 2 orders of magnitude greater than that reported to reduce naupliar survival of $A$. tonsa. The 96-h $\mathrm{LC}_{95}$ cupric ion activity value for adult $T$. Californicus is $3.3 \times 10^{-7} M_{1}$ approximately 3 orders of magnitude greater than the value causing total mortality in $A$. tonsa and $C$. typicus.

To summarize, it appears from the comparison with data from other copepods that Tigriopus californicus has a higher tolerance to excess biologically avaliable copper. This inference is especially valid if the LC values previously reported from seawater were affected by natural organic complexing agents. Earlier work was often with natural seawater and expressed as a function of total copper. In fact, toxicity must be measured in terms of metal bioavailability (cf. Sunda et al. 1987) rather than total metal.

The habitat occupied by Tigriopus californicus may explain part of its tolerance to excess copper. The extremes of temperature and salinity found in supratidal splash pools select for tolerant organisms. Changes in $\mathrm{pH}$ and organic matter in these splashpools will produce natural changes in metal bioavailability that could condition the species to tolerate changes. The chemistry of the organism will also play some role in metal tolerance. The presence of any chitin would provide an important metal sorbing and complexing agent (Subramanian et al. 1974). Any metallothioneinlike proteins would allow metal complexation and increase metal tolerance (e.g. Roesijadi 1981). However, it is important to recognize that innate tolerance to natural conditions is an expression of the genotype (e.g. Bradley 1986) which, at least in plants (e.g. Humphreys \& Nicholls 1984), plays an important role in metal tolerance. Thus organisms like $T$. californicus, which live under wide-ranging environmental conditions, may have an innate ability to tolerate excess metal. This provides support for the hypothesis that naturally tolerant organisms are better able to live in habitats exposed to pollutants than would less tolerant species. From a practical standpoint, this must be considered in the selection of a species for bioassay purposes.

Acknowledgements. Support for this work was received from the International Copper Research Association, Inc, and from the Natural Science and Engineering Research Council of Canada. Dr Peter Chapman, Louise Wootton and Anna Metaxas were kind enough to review the manuscript and offer suggestions for its improvement.

\section{LITERATURE CITED}

Bradley, B. P. (1986). Genetic expression of temperature tolerance in the copepod Eurytemora affinis in different salinity and temperature environments. Mar. Biol. 91: 561-565

Burton, R. S. (1985). Mating system of the intertidal copepod Tigriopus californicus. Mar. Biol. 86: 247-252

Burton, R. S., Feldman, M. W., Curtsinger, J. W. (1979). Population genetics of Tigriopus californicus (Copepoda: Harpacticoida): 1. Population structure along the Central California coast. Mar. Ecol. Prog. Ser 1. 29-39

Dethier, M. N. (1980). Tidepools as refuges: predation and the limits of the harpacticoid copepod, Tigriopus californicus (Baker). J. exp. mar. Biol. Ecol. 41: 99-111.

Fraser, J. H. (1936). The occurrence, ecology and life history of Tigriopus fulvus (Fischer). J. mar. biol. Ass. U. K. 20 523-536

Harris, R. P. (1973). Feeding, growth, reproduction and nitrogen utilization by the harpacticoid copepod. Tigriopus brevicornis. J. mar. biol. Ass. U. K. 35: 785-800

Huizinga, H. W. (1971). Cultivation, life history and salinity tolerance of the tidepool copepod, Tigriopus californicus Baker 1912, in artificial sea water Trans. Ill. State Acad. Sci. $64: 230-236$

Humphreys, M. O., Nicholls, M. K. (1984). Relationships between tolerance to heavy metals in Agrostis capillaris L. (A. tenuis Sibth.). New Phytol. 98: 177-190

Luoma, S. N., Cain, D. J., Ho, K., Hutchinson, A. (1983). Variable tolerance to copper in two species from San Francisco Bay. Mar. environ. Res. 10: 209-222

Millero, F. J., Schreiber, D. R. (1982). Use of the ion pairing model to estimate activity coefficients of the ionic components of natural waters. Am. J. Sci. 282: 1508-1540

Moraitou-Apostolopoulou, M. (1978). Acute toxicity of copper to a copepod. Mar. Pollut. Bull. 9: 278-280

Moraitou-Apostolopoulou, M., Verriopoulos, G. (1979). Some effects of sub-lethal concentrations of copper on a marine copepod. Mar. Pollut. Bull. 10: 88--92

Morel, F. M. M., Rueter, J. G., Anderson, G. M., Guillard, R. R. L. (1979). Aquil: a chemically defined phytoplankton culture medium for trace metal studies. J. Phycol. 15 135-141

Reeve, M. R., Grice, G. D., Gibson, V. R., Walter, M. A., Ikeda, T. (1976). A controlled environmental pollution experiment (CEPEX) and its usefulness in the study of larger marine 
zooplankton under toxic stress. In: Lockwood, A. P. M. (ed.) Society for experimental biology seminar series, Vol. 2. Effects of pollutants on aquatic organisms seminar, 11 April 1975, Liverpool, England. Cambridge University Press, Cambridge, p. 145-162

Ritz, D. A. (1980). Fluctuations of intertidal amphipods to fluctuating conditions of salinity, oxygen and copper. J. mar biol. Ass. U. K. 60: 489-498

Roesijadi, G. (1981). The significance of low molecular weight, metallothionein-like proteins in marine invertebrates; current status. Mar. environ. Res. 4: 167-179

Sabourin, T. D., Gant, D. B., Weber, L. J. (1985). The influence of metal and nonmetal stressors on hepatic metal-binding protein production in buffalo sculpin, Enophrys bison. In: Vernberg, F. J., Thumberg, F. P., Calabrese, A., Vernberg, W. (eds.) Marine pollution and physiology: recent advances. University of South Carolina Press, Columbia, S. C., p. $247-266$

Standard Methods (1976). Standard methods for the examination of waste and wastewater. Am. Public Health Ass., Washington, D. C.

Subramanian, T., Yoshinari, T., d'Anglejan, B. (1974). Studies on the formation of chitin-metal complexes. M. S.C.
Manuscript Report No. 27: 1-75 (Mar. Sci. Cent., McGill Univ., Montreal, Quebec, Canada)

Sunda, W. G., Tester, P. A., Huntsman, S. A. (1987). Effects of cupric and zinc ion activities on the survival and reproduction of marine copepods. Mar. Biol. 94: 203-210

Turner, D. R., Whitfield, M., Dickson, A. G. (1981). The equilibrium speciation of dissolved components in freshwater and seawater at $25^{\circ} \mathrm{C}$ and $1 \mathrm{~atm}$ pressure. Geochim. Cosmochim. Acta 45: 855-881

Verriopoulos, G., Moraitou-Apostolopoulou, M. (1982). Differentiation of the sensitivity to copper and cadmium in different life stages of a copepod. Mar. Pollut. Bull. 13: $123-125$

Wood, A. M. (1983). Available copper ligands and the apparent bioavailability of copper to natural phytoplankton assemblages. Sci. total Environ. 28: 51-64

Wood, A. M., Evans, D. W., Alberts, J. J. (1983). Use of an ion exchange technique to measure copper complexing capacity on the continental shelf of the southeastern United States and in the Sargasso Sea. Mar. Chem. 13: 305-326

Zar, J. H. (1984). Biostatistical analysis. Prentice-Hall, Inc., New Jersey

This article was submitted to the editor; it was accepted for printing on February 9, 1988 